\title{
SISTEM PELAYANAN BANTUAN MENTOR BIMBINGAN BELAJAR (BAMBIMBEL) BERBASIS WEB
}

\author{
Fadhli Ranuharja ${ }^{1}$, Bayu Ramadhani Fajri ${ }^{2}$, Agariadne Dwinggo Samala ${ }^{3}$ \\ ${ }^{123}$ Program Studi Pendidikan Teknik Informatika, Universitas Negeri Padang, Indonesia \\ Jl. Prof. Hamka Kampus UNP Air Tawar Padang \\ *Corresponding Author: fadhliranu@ft.unp.ac.id
}

\begin{abstract}
ABSTRAK
Adanya tuntutan penerimaan mahasiswa baru dengan menggunakan ujian Seleksi Nasional Perguruan Tinggi Negeri (SNMPTN) di Indonesia, siswa lulusan SMA/SMK diharapkan menguasai beberapa mata pelajaran dasar. Berdasarkan data primer wawancara penjurusan siswa yang dilakukan SMA/SMK di Indonesia belum cukup untuk membekali siswa dalam persiapan mengikuti ujian seleksi nasional,layanan bimbingan belajar didominasi jumlah terbanyak di kota besar, kemudian mahalnya biaya bimbingan belajar membuat siswa sulit punya kesempatan untuk mengikuti bimbingan belajar sehingga perlu dirancang sistem pelayanan bimbingan belajar yang dapat diikuti oleh siswa tanpa dibatasi ruang dan waktu. Salah satunya adalah sistem bimbingan belajar berbasis web. Bimbingan belajar termasuk salah satu Pendidikan non-formal. Tujuan dari penelitian ini adalah merancang dan menghasilkan sebuah sistem pelayanan bantuan mentor bimbingan belajar (BAMBIMBEL). Mentor dari BAMBIMBEL adalah mahasiswa, sementara peserta didik BAMBIMBEL adalah siswa SMA/SMK di Kota Padang. Selain sebagai tempat mengasah kemampuan praktek mengajar oleh mahasiswa sebagai mentor, BAMBIMBEL juga memfasilitasi siswa yang ingin belajar untuk persiapan seleksi perguruan tinggi negeri. Metode yang digunakan adalah metode perancangan sistem berbasis web dengan pemodelan Unified Modeling Language (UML), pengujian sistem menggunakan metode Black Box, berdasarkan pengujian yang diamati dapat disimpulkan hasil eksekusi melalui data uji dan fungsionalitas dari sistem BAMBIMBEL berjalan dengan baik dan sesuai dengan yang diharapkan.
\end{abstract}

Kata Kunci: Sistem Pengambilan Keputusan, Mentor, Framework Laravel

\begin{abstract}
The existence of demands for the acceptance of new University students by using the national selection exam of National University in Indonesia, student high school / vocational high school graduates are expected to master a number of basic subjects. Based on the primary data, the result of students' interview in choosing the majors for college which was conducted in Senior High School / Vocational High School in Indonesia are insufficient for the students to take the national exam. This learning course services has high frequency in the big city, furthermore expensiveness of non formal courses made student has low chance follow non formal courses. Based on this reason need to build learning course system that able followed up by student without limit by time and place. One of those solution is by making learning courses services. It was one kind of non formal courses. The purpose of this study is to produce a service system in the form of giving the facilities for students to abilities in teaching practice and facilitate students who want to learn but having a financial issue. It is expected that with the assistance by student teacher, it will be easier for other students to understand and gain sort of interest in the study. Based on the observation, both from the point of view of college students and the point of view of high school / vocational high school students, then it is considered essential to create this service system. Learning with this tutoring facility is very effective because it directly encourages the students in the competency section that they do not fully understand with the help of tutors who have a better understanding. The method used is a web-based system design with UML modelling, using use case diagrams, activities, collaborations and class diagrams to plan the flow of data transactions that exist in the mentoring assistance service system of tutoring.
\end{abstract}

Keywords: Decision Support System, Mentor, Laravel Framework 


\section{PENDAHULUAN}

Ujian Seleksi Nasional Perguruan Tinggi adalah sebuah proses yang wajib dilalui siswa untuk mengukur kemampuan minat dan bakat siswa dengan tujuan agar dapat melanjutkan studi di perguruan tinggi yang diinginkan. Ujian Nasional yang didikuti siswa SMA dan SMK saat ini berupa UTBK. UTBK adalah ujian nasional yang diselenggarakan pemerintah pelaksanaanya wajib menggunakan Komputer. Berdasarkan Peraturan Menteri Pendidikan dan Kebudayaan Republik Indonesia No 6 Tahun 2020 tentang penerimaan mahasiswa baru program sarjana pada perguruan tinggi negeri disebutkan bahwa Jalur penerimaan mahasiswa baru Program Sarjana pada PTN dilakukan melalui seleksi nasional masuk Perguruan Tinggi Negeri dalam bentuk UTBK.

Siswa SMA dan SMK atau sederajat diberikan pembekalan sebelum mengikuti ujian. Pembekalan ilmu ini dilakukan oleh pihak sekolah secara intensif. Pembekalan ini dilakukan 3 kali dalam seminggu dalam bentuk tryout atau membahas soal. Berdasarkan hasil wawancara dengan SMAN 1, SMAN 3, SMKN 2 dan SMKN 5 di kota Padang try out dilaksanakan hamper setiap minggu. Dengan menggunakan metode try out ini pihak guru dan sekolah mengharapkan hasil yang baik untuk siswa berhasil lulus Ujian masuk perguruan tinggi yang diinginkan. Sayangnya para siswa merasa kurang menguasai materi dengan hanya mengikuti try out dan membahas soal dengan guru sekolah. Siswa SMA dan SMA membutuhkan pembekalan ilmu yang lebih di luar jam belajar di sekolah dan pembelajaran yang bersifat non formal agar siswa leluasa bertanya dan berdiskusi.

Program pendidikan non formal di luar sekolah dilaksanakan dengan metode mentoring. Mentoring adalah pemebelajaran yang dipimpin oleh seorang mentor/pendamping yang memiliki umur tidak beda jauh dengan siswa. Mentor berfungsi membimbing siswa memahami materi dengan cara diskusi Tanya jawab dan monitoring hasil belajar siswa. Umur yang tidak jauh dengan siswa menjadikan proses diskusi dan Tanya jawab semakin leluasa. Sehingga siswa bebas bertanya tentang hal-hal kecil yang ragu untuk ditanyakan sewaktu belajar di sekolah formal. Diharapkan dengan mengikuti belajar non formal mentoring ini siswa lebih menguasai materi yang akan diujikan saat UTBK.

Biaya bimbingan belajar siswa SMA/SMK untuk lolos tes ke Perguruan Tinggi [2] sangat mahal. Sehingga banyak mahasiswa tidak mampu untuk mengikuti bimbingan belajar. Seperti di Kota Padang terutama sudah banyak lembaga bimbingan belajar yang berdiri, mulai dari bimbingan untuk ujian sampai dengan bimbingan untuk lomba. Lembaga bimbel ini berbentuk komersil, dan untuk biaya pendaftaran sampai dengan bimbingan tidak semua siswa dapat menyanggupinya. Untuk itu diperlukan sebuah badan bimbingan belajar yang menampung siswa tidak mengacu pada keuntungan semata.

Siswa lebih bisa memahami pelajaran jika bertanya kepada orang yang umurnya tidak terpaut jauh darinya [3]. Hal tersebut disimpulkan berdasarkan observasi yang telah dilakukan. Siswa cenderung pasif dan hanya mendengarkan penjelasan guru di kelas. Sedangkan jika teman sebaya yang menerangkan siswa lebih antusias dan rajin menanyakan tentang materi pelajaran yang meragukan di kelas. Kemudian pembelajaran online atau pembelajaran berbasis ICT [4] ini dapat diakses menggunakan komputer ataupun smartphone tentu sangat diminati oleh siswa, mudah dalam penggunaan serta dapat dia diakses kapanpun dan dimanapun. [5]

\section{METODE}

Adapun metode perancangan yang digunakan adalah menggunakan pemodelan UML (Unified Modelling Language) karna dianggap paling mudah dimengerti oleh perancang maupun umum. Pemodelan UML adalah sebuah teknik yang memusatkan desain pada objek dan class berdasarkan pada skenario dunia nyata. UML (Unified Modeling Language) yang berarti bahasa pemodelan standar[6].

Untuk perancangan sistem pelayanan terintegrasi pemodelan berbasis UML cukup untuk memetakannya mulai dari analisis user, analisis activity, kemudian di rancang ulang menjaadi database yang utuh disarankan menggunakan pemodelan UML[7]

\section{HASIL DAN PEMBAHASAN}

\section{A. Analisis Sistem}

\section{Analisis User}

Analisis kebutuhan user pada intinya memfasilitasi pengguna yaitu orang yang akan membimbing (mentor) dan calon peserta didik yang ingin bimbingan belajar (siswa). Mentor sebagai pembimbing belajar siswa dapat mencantumkan CV atau portofolio di halaman profil sehingga calon siswa tertarik dan dapat memilih mentor tersebut. User dari sistem pelayanan BAMBIMBEL ini adalah mentor, siswa dan calon siswa (pengunjung). 


\section{Analisis Input}

Beberapa data yang telah dianalisa sebagai input yang akan dimasukkan adalah data calon mentor dan siswa yang telah terdaftar pada sistem web dengan cara mendaftar pada situs web melalui menu register. Khusus untuk mentor akan diberlakukan aturan khusus demi keamanan dan kepercayaan calon siswa yang keseluruhannya diawasi oleh admin yang ada pada bimbingan belajar web tersebut.

\section{Analisis Output}

Tampilan hasil analisa output yang dihasilkan sistem ini dirancang untuk memudahkan pengguna memanajemen bimbingan belajar. Output yag dihasilkan dari segi operator web yakni laporan user yang sudah terdaftar di sistem, laporan berapa mata pelajaran yang tersedia di sistem, laporan kemajuan bimbingan belajar, laporan data mata pelajaran siswa individu yang telah diambil dan yang terakhir laporan informasi web. Output dapat berupa .pdf maupun file excel yang dapat dicetak baik oleh operator web maupun mentor.

\section{B. Perancangan Sistem}

\section{Statement of Purpose}

Sistem pelayanan bantuan mentor bimbingan belajar berbasis web adalah sebuah sistem yang menyediakan layanan bagi mahasiswa sebagai mentor yang ingin mengajar dan siswa yang menginginkan bimbingan belajar. Keduanya terintegrasi ke dalam sistem sehingga memudahkan untuk melakukan proses bimbingan belajar di luar sekolah. Jadi, mentor adalah mahasiswa pada peguruan tinggi, sedangkan siswa adalah murid dari sekola menengah atas dan sekolah menengah kejuruan.

\section{Analisis Pengguna Sistem}

Tahap ini menjelaskan hak akses atau user dari sistem yang akan dibangun. Pada sistem ini terdapat beberapa jenis pengguna sistem yaitu:

a) Admin atau Operator, orang yang mengelola keseluruhan manajemen user, kelas dan informasi yang ada di sistem.

b) Mentor, adalah mahasiswa UNP yang divalidasi oleh admin. Mentor dapat membuat Teaching Course Room (Ruang Bimbingan Belajar di sistem)

c) Siswa, adalah user yang telah terdaftar sebagai siswa bimbingan belajar, dan dapat mengikuti bimbingan belajar pada TCR yang tersedia. d) Pengunjung, adalah pengunjung web atau visitors biasa yang hanya mengakses web saja tanpa terdaftar sebagai admin, mentor ataupun siswa.

Diagram konteks mempunyai aliran yang memodelkan masukan ke sistem dan keluaran dari sistem, yang diperlukan untuk mendeteksi kejadian dalam lingkungan dimana sistem harus memberikan respon atau membutuhkan data untuk menghasilkan respon. Selain itu aliran data dibutuhkan untuk menggambarkan transportasi antara sistem dan terminator. Diagram konteks pada Gambar 1 menjelaskan siapa saja yang berperan dalam Sistem Pelayanan Bantuan Bimbingan Belajar.

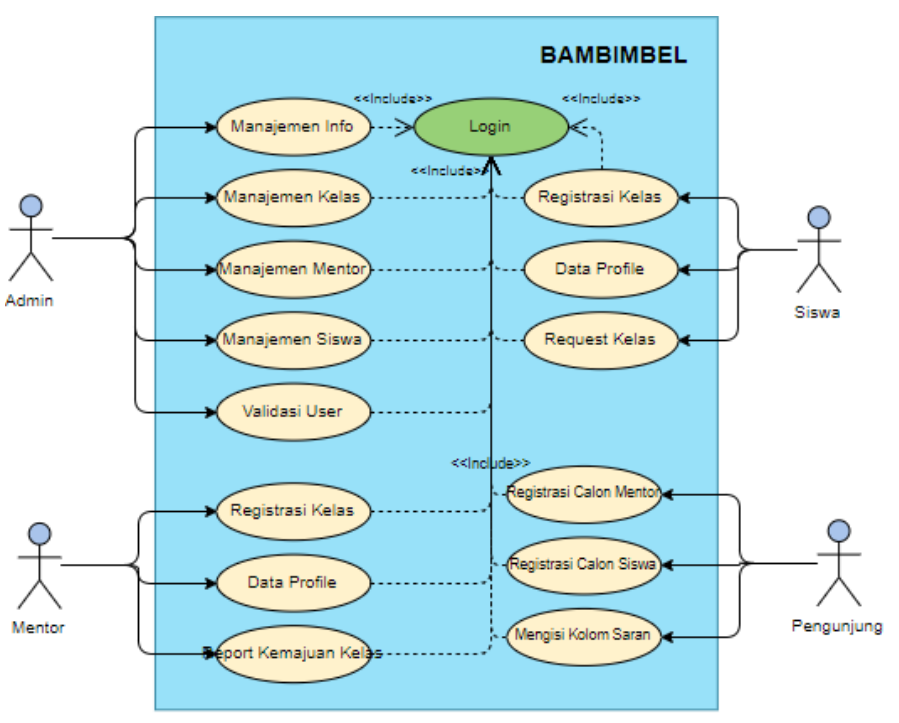

Gambar 1. Diagram Use Case Sistem Pelayanan BAMBIMBEL

Pada Use Case Diagram terdapat empat pengguna dalam sistem yaitu admin, mentor, siswa, dan pengunjung. Untuk mentor dapat melakukan manajemen info, manajemen kelas, manajemen mentor, manajemen siswa, dan melakukan validasi user (mengelola role dari user). Untuk mentor dapat membuka kelas, melihat data profile, dan melihat laoran kemajuan kelas. Untuk siswa dapat melakukan pendaftaran ke dalam kelas yang tersedia, melihat data profile, dan melakukan request pembukaan kelas baru. Sedangkan pengunjung biasa atau visitors merupakan pengguna yang hanya mengunjungi sistem pelayanan BAMBIBEL tanpa melakukan pendaftaran akun. Pengunjung memiliki batas akses ke dalam sistem. Pengunjung hanya dapat mengisi kolom saran, dan dapat mendaftar sebagai siswa atau mentor. Untuk lebih jelas dapat dilihat pada Gambar 2 yang merupakan konteks diagram dari sistem pelayanan BAMBIMBEL yang dikembangkan. 


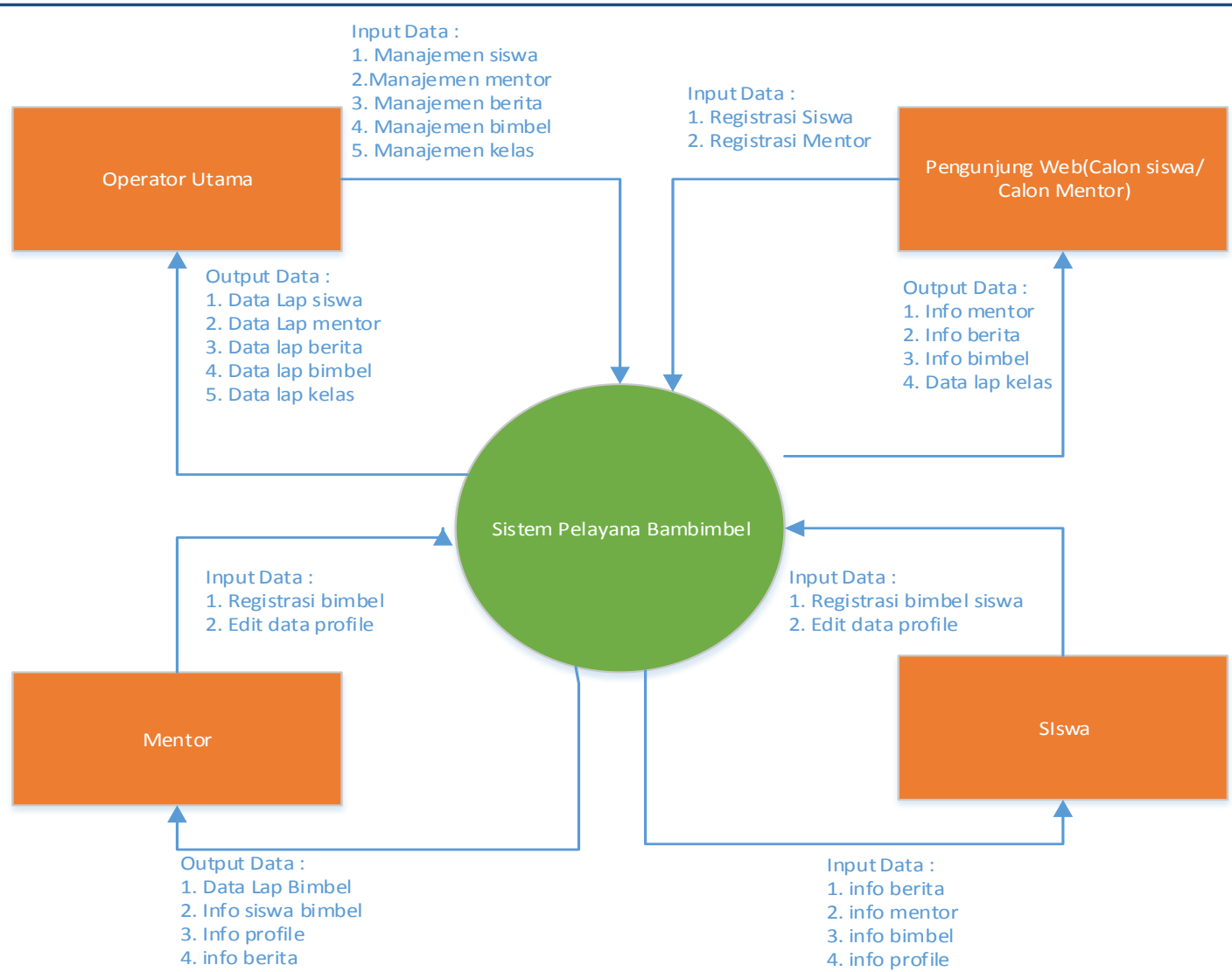

Gambar 2. Diagram Konteks Sistem Pelayanan BAMBIMBEL

Activity Diagram merupakan gambaran secara umum dari sistem yang dirancang, serta berguna untuk membantu memahami proses yang terjadi pada sistem pelayanan bantuan bimbingan belajar.

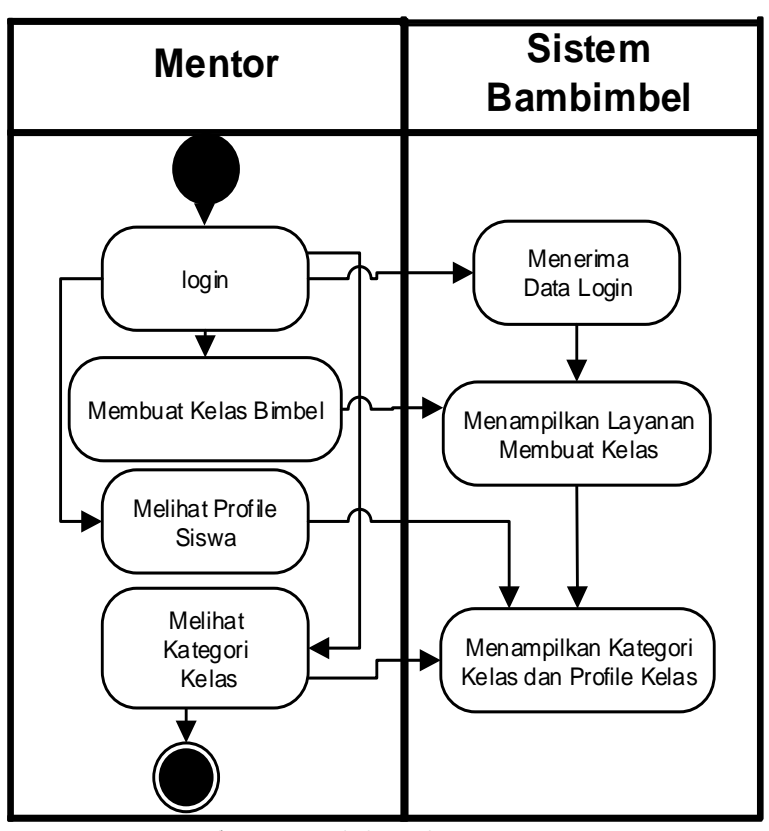

Gambar 3. Activity Diagram Mentor

Gambar 3 menjelaskan aktifitas user dari sistem yaitu mahasiswa yang memiliki hak akses mentor dimulai dari login status user sebagai mentor. Data login tersebut diterima oleh sistem dan dilakukan pengecekan status login user, jika benar maka user sebagai mentor memiliki layanan untuk membuat TCR (Teaching Course Room) kelas mentoring, melihat siswa kelas dan melihat profil siswa di dalamnya.

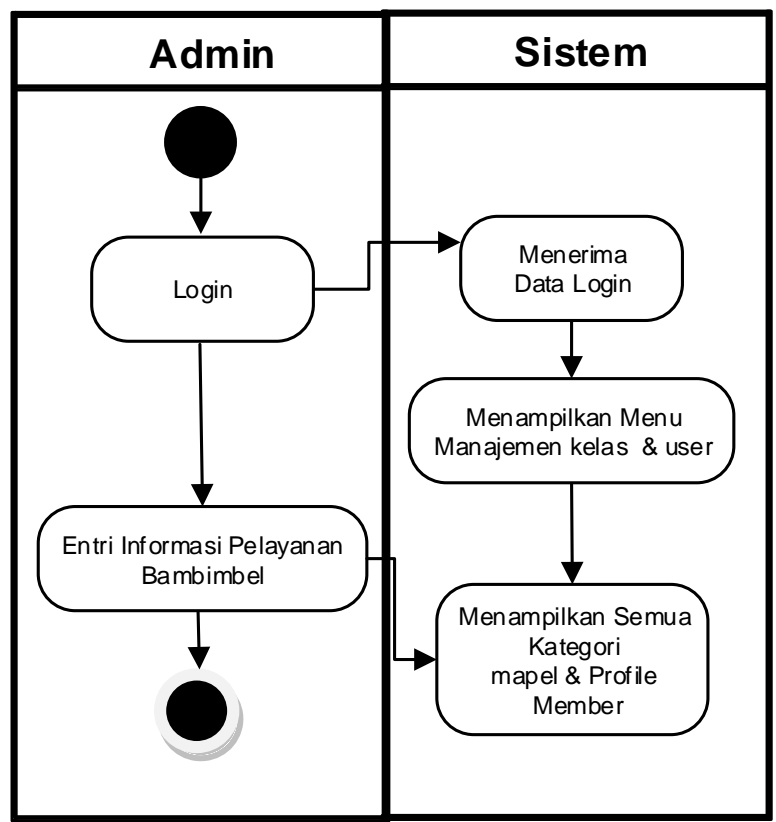

Gambar 4. Activity Diagram Admin 
Pada Gambar 4 diatas, pada titik awal admin melakukan login terhadap sistem, setelah sistem menerima data login, admin dapat melihat informasi, laporan yang diinginkan dan mengubah atau menambah data kelas dan data profil member. Sebelum mendapatkan table yang tetap dilakukan uji normalisasi. Uji normalisasi ini bertujuan agar attribute-attribut dalam table tidak mengalami perulangan disebutkan oleh table lain, dan setiap table jelas memiliki ciri khas yang khusus

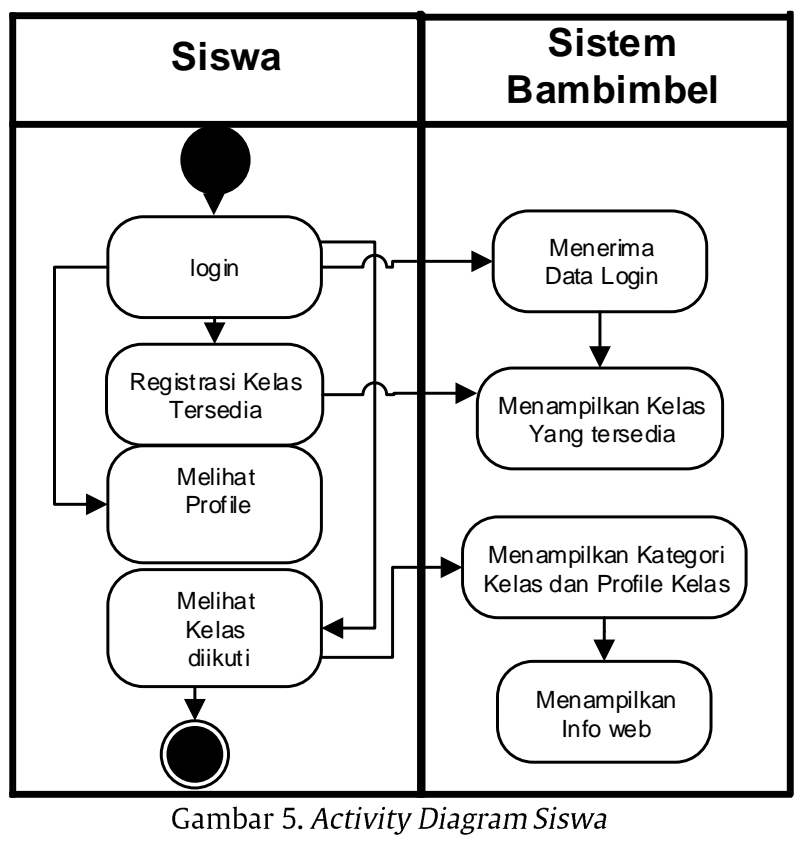

Gambar 5 Diagram activity dengan hak akses siswa menjelaskan alur aktitivas kegiatan alur aktitivas kegiatan yang dapat dilakukan oleh hak akses siswa berupa login, registrasi kelas, melihar profil dan melihat kelas yang telah diikuti. Setiap kali siswa login sistem akan membuatkan session baru yag akan menampilkan menu siswa, tentu melalui proses verifikasi login. Kemudian pada menu tersebut ada tombol registrasi kelas yang dapat memunculkan kelas-kelas yang tersedia untuk didaftarkan. Dan menu yang lainnya melihat profile user siswa yg login lalu menu melihat kelas yang diikuti.

Halaman utama adalah pintu gerbang akses utama baik user admin, mentor, siswa maupun pengunjung yang ingin masuk ke dalam website. Beberapa fitur yang dapat diakses dibagi menjadi beberapa kelompok besar yaitu : pertama menu bar navigasi untuk akses login, mentor-mentor bidang matapelajaran favorit, fitur pemilihan bimbingan bantuan mentor bimbingan belajar berdasarkan tingkat kelas di sma mulai dari kelas X, XI dan XII, kemudian di halaman utama juga terdapat pojok berita yang memuat info terkini terkait dengan pembukaan bidang mata pelajaran baru maupun info lain yang berhubungan dengan bimbingan belajar.

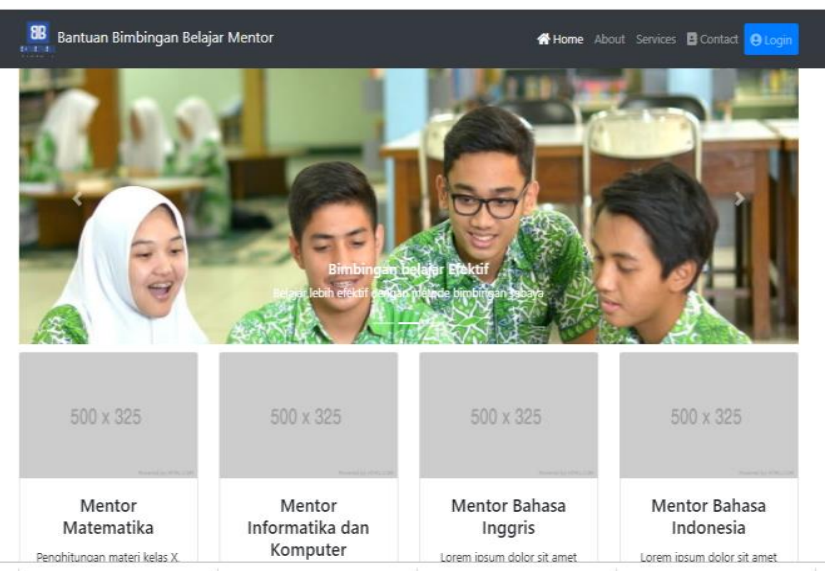

Gambar 6. Halaman Utama BAMBIMBEL

\section{Hasil Pengujian}

Pengujian metode black box merupakan pengujian terhadap fungsionalitas input/output dari suatu perangkat lunak atau sistem [8]. Ujicoba BlackBox dilakukan untuk menemukan kesalahan dalam beberapa kategori yaitu :

1) Fungsi-fungsi yang hilang atau salah

2) Kesalahan desain antarmuka (interface) atau tampilan

3) Kesalahan dalam struktur data atau akses database ekternal

4) Kesalahan performa

5) Kesalahan inisialisasi dan terminasi

Berikut hasil pengujian sistem BAMBIMBEL menggunakan metode black box testing dapat dilihat pada tabel 1 berikut

Tabel 1. Hasil Pengujian Sistem BAMBIMBEL

\begin{tabular}{lllc}
\hline No & Skenario & Testing & Hasil \\
Pengujian
\end{tabular}




\begin{tabular}{lllc}
\hline \hline No & \multicolumn{1}{c}{ Skenario } & Testing & $\begin{array}{c}\text { Hasil } \\
\text { Pengujian }\end{array}$ \\
\hline 6 & Admin melalukan Manajemen Informasi & Add, Edit, Del Informasi & OK \\
\hline 7 & Admin melalukan Manajemen Siswa & Add, Edit, Del Siswa & OK \\
\hline 8 & Admin melakukan validasi user & Accept, Reject & OK \\
\hline 9 & Mentor mendaftar kelas & Join Kelas & OK \\
\hline 10 & Mentor mengelola data profile & Edit, Save Profile & OK \\
\hline 11 & Mentor membuat laporan kemajuan kelas. & Add, Edit, Del, View, Download & OK \\
\hline 12 & Siswa mendaftar kelas & Join Kelas & OK \\
\hline 13 & Siswa mengelola data profile & Edit, Save Profile & OK \\
\hline 14 & Siswa request kelas & Request Kelas & OK \\
\hline 15 & Pengunjung mengisi kolom komentar & Add Comments & OK \\
\hline 16 & Siswa mengakses materi & View File & OK \\
\hline 17 & Pengaksesan menggunakan Komputer dan Smartphone & PC / Android / IOS & OK \\
\hline 18 & Output laporan kemajuan kelas berupa pdf dan file excel & Download File Laporan & OK \\
\hline
\end{tabular}

\section{KESIMPULAN}

Sistem pelayanan bimbingan belajar (BAMBIMBEL) ini dirancang dengan menggunakan pemodelan UML di mulai dari analisis user, sistem dan aktivitas yang dilakukan oleh pengguna sistem, serta pengujian secara fungsionalitas sistem sehingga menghasilkan sebuah sistem yang dapat memenuhi kebutuhan siswa sekolah dan mahasiswa sebagai mentor dalam mengadakan pendidikan nonformal[9].

Pengujian fungsionalitas dari BAMBIMBEL yang dirancang menggunakan metode black box testing menunjukkan bahwa BAMBIMBEL dapat menampilkan output atau memberikan respon sesuai dengan yang diminta berdasarkan masingmasing roles pengguna yang ada pada sistem, baik sebagai admin, mentor, siswa, dan pengunjung biasa[10].

Proses registrasi dan login setiap roles dari user dapat berjalan dengan baik, kemudian semua fungsi dari masing-masing roles diuji dan memberikan hasil pengujian yang baik. Hal ini menunjukkan bahwa BAMBIMBEL berjalan dengan baik sesuai dengan yang diharapkan. Dari 18 skenario pengujian yang dilakukan memberikan hasil OK untuk setiap scenario seperti pada tabel 1 .

Dari hasil perancangan sistem ini dapat ditarik kesimpulan bahwa:

1. Sistem bantuan bimbingan belajar ini membantu siswa dalam penguatan materi sekolah maupun materi matapelajaran lain yang tidak diajarkan di sekolah di jurusannya untuk mendapatkan kelulusan di ujian seleksi nasional perguruan tinggi.

2. Mahasiswa dapat melatih kemampuan mereka menjadi calon guru non formal selain menggunakan program praktek lapangan yang biasanya hanya ada pada semester akhir.

3. Sistem pelayanan BAMBIMBEL secara digital dapat menghemat waktu dan tenaga siswa dan mahasiswa untuk bergabung dengan tempat bimbingan les belajar non formal.

\section{SARAN}

Sistem ini dapat dikembangkan lagi untuk umum umum yang tidak memiliki latar belakang pendidikan sebagai peserta didik, dan ahli pakar yang benar benar berkompetensi di bidangnya sebagai mentor.

\section{DAFTAR PUSTAKA}

[1] F. F. Hanum and Suprayekti, "PENERAPAN TEKNOLOGI PENDIDIKAN DI LEMBAGA PENDIDIKAN NONFORMAL," JIV-Jurnal Ilm. Visi, vol. 14, no. 1, pp. 1-16, Jun. 2019.

[2] Y. Hartadi, H. Suryamen, and F. Akbar, "Perancangan Sistem Informasi Lokasi Lembaga Bimbingan Belajar di Kota Padang," J. Nas. Teknol. dan Sist. Inf., vol. 2, no. 1, pp. 35-44, Apr. 2016.

[3] M. Zainil, R. C. I. Prahmana, Y. Helsa, and S. Hendri, "ICT media design for higher grade of elementary school mathematics learning using CS6 program," J. Phys. Conf. Ser., vol. 943, p. 012046, Dec. 2017.

[4] G. Ganefri, B. R. Fajri, F. Ranuharja, F. Prasetya, R. Fadillah, and F. Firdaus, "MINI SERVER LENTERA SEBAGAI ALTERNATIF PEMBELAJARAN DIGITAL DI DAERAH 3T," J. Teknol. Inf. dan Pendidik., 2019.

[5] A. D. Samala, B. R. Fajri, and F. Ranuharja, "DESAIN DAN IMPLEMENTASI MEDIA PEMBELAJARAN BERBASIS MOBILE LEARNING MENGGUNAKAN MOODLE MOBILE APP," J. 
Teknol. Inf. dan Pendidik., vol. 12, no. 2, pp. 13-19, Dec. 2019.

[6] S. Ain El Hayat, F. Toufik, and M. Bahaj, "UML/OCL based design and the transition towards temporal object relational database with bitemporal data," J. King Saud Univ. Comput. Inf. Sci., Aug. 2019.

[7] F. Ranuharja, Oktoria, and N. Dwiyani, "Perancangan Sistem Informasi Jasa Penjualan Barang Berbasis Web Untuk Civitas Akademika Perguruan Tinggi di Kota Padang," J. Vocat. Tek. Elektron. dan Inform., vol. 2, no. 2, pp. 1689-1699, 2014.

[8] A. Purnomo, "Software Testing Aplikasi Website PT Gramedia Menggunakan Metode Blackbox pada PT WGS Bandung," vol. 91, pp. 399-404, 2017.

[9] K. Siau and P.-P. Loo, "Identifying Difficulties in Learning Uml," Inf. Syst. Manag., vol. 23, no. 3, pp. 43-51, Jun. 2006.

[10] A. S. Aydiner, E. Tatoglu, E. Bayraktar, and S. Zaim, "Information system capabilities and firm performance: Opening the black box through decision-making performance and business-process performance," Int. J. Inf. Manage., vol. 47, pp. 168-182, Aug. 2019. 